\title{
Colitis, CTCAE
}

National Cancer Institute

\section{Source}

National Cancer Institute. Colitis, CT CAE. NCI Thesaurus. Code C57134.

A disorder characterized by inflammation of the colon. 